\title{
FLORÍSTICA E ESTRUTURA DO COMPONENTE ARBÓREO E ANÁLISE AMBIENTAL DE UM FRAGMENTO DE FLORESTA OMBRÓFILA MISTA ALTO-MONTANA NO MUNICÍPIO DE PAINEL, SC
}

\author{
FLORISTIC COMPOSITION AND STRUCTURE OF THE TREE COMPONENT AND \\ ENVIRONMENTAL ANALYSIS OF A FRAGMENT OF A HIGHLAND ARAUCARIA FOREST IN \\ THE MUNICIPALITY OF PAINEL, SANTA CATARINA STATE
}

Pedro Higuchi ${ }^{1}$ Ana Carolina da Silva ${ }^{2}$ Jaime Antonio de Almeida ${ }^{3}$ Roseli Lopes da Costa Bortoluzzi ${ }^{4}$ Adelar Mantovani $^{5}$ Tiago de Souza Ferreira ${ }^{6}$ Sheila Trierveiler de Souza ${ }^{7}$ Juliano Pereira Gomes ${ }^{8}$ Karina Montibeller da Silva ${ }^{8}$

\section{RESUMO}

A Floresta Ombrófila Mista Alto-Montana é uma formação pouco estudada que ocorre em altitudes acima de $1.000 \mathrm{~m}$. Os objetivos deste estudo foram conhecer os padrões florísticos e estruturais do componente arbóreo de um fragmento desta floresta na região do Planalto Sul Catarinense e determinar as variáveis ambientais que influenciam esses padrões. O levantamento da composição florística e estrutural e a coleta das variáveis ambientais foram conduzidos em 50 parcelas de $200 \mathrm{~m}^{2}$. Nelas, todos os indivíduos arbóreos com CAP (circunferência medida a altura do peito) $\geq 15,7 \mathrm{~cm}$ foram medidos (CAP e altura) e identificados. Foram coletadas, em cada parcela, variáveis ambientais relacionadas às características químicas e físicas dos solos, topográficas e de cobertura do dossel. Foram calculados os parâmetros fitossociológicos e a estrutura diamétrica da comunidade e das populações com valor de importância (VI) acima de $5 \%$. A similaridade florístico-estrutural entre as parcelas foi analisada pela NMDS (Nonmetric Multidimensional Scaling) e os vetores das variáveis ambientais significativas $(p<0,05)$ foram plotados a posteriori. Foram identificadas 50 espécies arbóreas distribuídas em 33 gêneros e 20 famílias botânicas. As espécies com maior VI foram: Araucaria angustifolia (Bertol.) Kuntze (17,32 \%), Myrceugenia euosma (O.Berg) D.Legrand (15,24 \%) e Acca sellowiana (O.Berg) Burret (7,84 \%). A estrutura diamétrica de toda a comunidade e das populações estudadas (exceto Dicksonia sellowiana Hook.) teve distribuição próxima ao "J invertido". A análise NMDS demonstrou maior porcentagem de argila nas parcelas com maior densidade de Araucaria angustifolia e

1. Engenheiro Florestal, Dr., Professor do Departamento de Engenharia Florestal, Centro de Ciências Agroveterinárias, Universidade do Estado de Santa Catarina, Av Luiz de Camões, 2090, Conta Dinheiro, CEP 88520-000, Lages (SC). higuchip@gmail.com

2. Engenheira Florestal, Dra., Professora do Departamento de Engenharia Florestal, Centro de Ciências Agroveterinárias, Universidade do Estado de Santa Catarina, Av Luiz de Camões, 2090, Conta Dinheiro, CEP 88520-000, Lages (SC). carol_sil4@yahoo.com.br

3. Engenheiro Agrônomo, Dr., Professor do Departamento de Solos e Recursos Naturais, Centro de Ciências Agroveterinárias, Universidade do Estado de Santa Catarina, Av Luiz de Camões, 2090, Conta Dinheiro, CEP 88520-000, Lages (SC). a2jaa@cav.udesc.br

4. Bióloga, Dra., Professora do Departamento de Engenharia Florestal, Centro de Ciências Agroveterinárias, Universidade do Estado de Santa Catarina, Av Luiz de Camões, 2090, Conta Dinheiro, CEP 88520-000, Lages (SC).a2rcb@cav.udesc.br

5. Engenheiro Agrônomo, Dr., Professor do Departamento de Engenharia Florestal, Centro de Ciências Agroveterinárias, Universidade do Estado de Santa Catarina, Av Luiz de Camões, 2090, Conta Dinheiro, CEP 88520-000, Lages (SC). a2ama@cav.udesc.br

6. Engenheiro Florestal, Centro de Ciências Agroveterinárias, Universidade do Estado de Santa Catarina, Av Luiz de Camões, 2090, Conta Dinheiro, CEP 88520-000, Lages (SC). tiagoferreiracac@hotmail.com

7. Acadêmica do Curso de Engenharia Florestal, Centro de Ciências Agroveterinárias, Universidade do Estado de Santa Catarina, Av Luiz de Camões, 2090, Conta Dinheiro, CEP 88520-000, Lages (SC). sheila tsouza@hotmail.com

8. Engenheiro Florestal, Mestrando do Programa de Pós-graduação em Produção Vegetal, Centro de Ciências Agroveterinárias, Universidade do Estado de Santa Catarina, Av Luiz de Camões, 2090, Conta Dinheiro, CEP 88520-000, Lages (SC). julianopgomes@yahoo.com.br / karynaflorestal@yahoo.com.br

Recebido para publicação em 22/11/2010 e aceito em 7/10/2011 
menor porcentagem, nas parcelas com maior densidade de Dicksonia sellowiana, Inga lentiscifolia Benth. e Ocotea pulchella Mart. As parcelas de maior declividade tiveram maior densidade de Drimys brasiliensis Miers e aquelas de menor declividade, maior cota e maior cobertura do dossel, tiveram maior ocorrência de Drimys angustifolia Miers, Prunus myrtifolia (L.) Urb., Calyptranthes concinna DC. e Myrceugenia oxysepala (Burret) D.Legrand \& Kausel.

Palavras-chave: floresta nebular; floresta de araucária; NMDS.

\begin{abstract}
The highland Araucaria Forest is a little-studied forest formation, occurring in altitudes above 1,000 m. The objectives of this study were to understand the structural and floristic patterns of the tree component of a remaining of this forest in the southern plateau region of Santa Catarina State and to determine the environmental variables that influence these patterns. The tree component survey and the environmental data collection were conducted in 50 plots of $200 \mathrm{~m}^{2}$. Within these plots, all living trees with circumference at breast height $(\mathrm{CBH}) \geq 15,7 \mathrm{~cm}$ were measured $(\mathrm{CBH}$ and height $)$ and identified. In each plot, environmental variables related to soils physical and chemical traits, topography and canopy cover were collected. Phytosociological parameters and the diameter structure (whole tree community and tree populations with the importance value above $5 \%$ ) were calculated. The floristic-structural similarities among plots were analyzed by NMDS (Nonmetric Multidimensional Scaling) and vectors of environmental variables $(\mathrm{p}<0.05)$ were plotted a posteriori. A total of 50 tree species were identified, distributed in 33 genera and 20 families. The species with the highest VI were Araucaria angustifolia (Bertol.) Kuntze (17.32\%), Myrceugenia euosma (O. Berg) D. Legrand (15.24 \%) and Acca sellowiana (O. Berg) Burret (7.84 \% ). The diameter structure of the whole community and of the study populations (except Dicksonia sellowiana Hook.) showed a distribution close to the "inverted J". The NMDS analysis showed a higher percentage of clay in the plots with the highest density of Acca sellowiana and lowest percentage in the plots with high density of Dicksonia sellowiana, Inga lentiscifolia Benth. and Ocotea pulchella Mart. Plots with higher declivity had a higher density of Drimys brasiliensis Miers and those of lower declivity, higher elevation and greater canopy closure, had a higher occurrence of Drimys angustifolia Miers, Prunus myrtifolia (L.) Urb, Calyptranthes concinna DC. and Myrceugenia oxysepala (Burret) D. Legrand \& Kausel.
\end{abstract}

Keywords: nebular forest; Araucaria Forest; NMDS.

\section{INTRODUÇÃO}

A Floresta Ombrófila Mista (FOM) se distribui no Planalto Meridional e em refúgios situados nas serras do Mar e da Mantiqueira, embora, em tempos pretéritos, tenha se expandido até mais ao norte do país (IBGE, 1992). Em termos de composição florística, a FOM é caracterizada pela presença de gêneros primitivos como Drimys, Araucaria (Australásicos) e Podocarpus (AfroAsiático) e não pode ser caracterizada como uma formação homogênea, podendo ser subdividida de acordo com a altitude e a proximidade do curso de água nas seguintes subformações: Aluvial, Submontana, em áreas com altitudes inferiores a $500 \mathrm{~m}$, Montana, com altitude entre 500 a $1.000 \mathrm{~m}$, e Alto-Montana, com altitudes superiores a $1.000 \mathrm{~m}$ (IBGE, 1992).

A floresta Alto-Montana, em Santa Catarina, forma áreas descontínuas, encontradas principalmente na borda oriental do Planalto, ou mais para o interior. Sua composição florística é bastante variável nos diferentes locais, com submata do pinheiro [Araucaria angustifolia (Bertol.) Kuntze] contínua formada pela imbuia associada com a sapopema (Sloanea monosperma Vell.) ou constituída principalmente por guamirins [Gomidesia sp., Myrcia bombycina (O. Berg) Kiaersk.], camboins [Siphoneugenia reitzii D. Legrand e Myrceugenia euosma (O.Berg) D. Legrand], entremeadas pela casca-d'anta (Drimys brasiliensis Miers) e pelas congonhas, pertencentes ao gênero Ilex (SANTA CATARINA, 1986).

O planalto catarinense está localizado na porção central do Estado e é formado por relevo que apresenta grande variação, ocorrendo desde relevo montanhoso a suave ondulado, com altitudes oscilando entre 700 a $1.800 \mathrm{~m}$ acima do nível do mar e com um gradiente altitudinal declinando no sentido Leste-Oeste. Dentre os municípios da região está Painel, que se situa acima de $1.000 \mathrm{~m}$. A vegetação desta região é formada por um mosaico 
de campos e Floresta Ombrófila Mista AltoMontana, adaptada a um inverno rigoroso com ocorrência de neve e geada. Como destacado por Koehler et al. (2002), o clima de áreas montanhosas desempenha forte influência sobre a composição florística e a estrutura do componente arbóreo. As áreas mais elevadas são comumente caracterizadas por temperaturas baixas, principalmente durante a noite, sendo também comum a formação de nuvens, o que caracteriza um ambiente nebular, com menor incidência de radiação solar e elevada umidade relativa do ar, o que conduz a uma baixa capacidade evapotranspirativa que, associada à predominância de solos pouco profundos, reflete em um ambiente ecologicamente seletivo.

As regiões alto-montanas do Planalto Sul Catarinense são consideradas estratégicas para a conservação, por apresentarem diversas nascentes de rios formadores da Bacia Hidrográfica do Rio Uruguai (SGROTT, 2003), tais como Canoas, Pelotas, Lava-Tudo e o Pelotinhas e estarem inseridas em uma área de recarga e afloramento do Aquífero Guarani (GOMES et al., 2006). Porém, pouco se conhece sobre os padrões estruturais e florísticos do componente arbóreo nessa região (KLEIN, 1978) e sua relação com o ambiente - destacando o estudo de Falkenberg (2003) - o que reforça a necessidade de estudos nestes locais visando gerar subsídios para planos de conservação e de recuperação de áreas impactadas pelo homem, ou para o uso sustentável dos recursos florestais nativos. Assim, o presente trabalho tem como objetivos i) conhecer os padrões florísticos e estruturais do componente arbóreo de um fragmento de Floresta Ombrófila Mista AltoMontana na Região do Planalto Sul Catarinense e ii) indicar possíveis variáveis ambientais que influenciam esses padrões.

\section{MATERIAL E MÉTODO}

\section{Área de estudo}

O fragmento de Floresta Ombrófila Mista Alto-Montana estudado localiza-se no município de Painel, no Planalto Sul do estado de Santa Catarina, na latitude de $27^{\circ} 55^{\prime} 44^{\prime \prime}$ 'S e longitude de $50^{\circ} 06^{\prime} 18^{\prime \prime} \mathrm{W}$ (Figura 1), com uma área total de 48,91 ha e altitude média de $1.399 \mathrm{~m}$. A região possui clima $\mathrm{Cfb}$, de acordo com a classificação de Köppen, e a precipitação média anual varia entre 1.200 a $1.900 \mathrm{~mm}$, com chuvas bem distribuídas durante o ano. A temperatura média anual registrada é de 15 a $16^{\circ} \mathrm{C}$, sendo que as temperaturas baixas do inverno facilitam a ocorrência de geadas e neve.

Painel está inserido na Bacia Hidrográfica do Rio Canoas, sendo que, na área estudada, as parcelas foram localizadas em áreas de relevo principalmente, ondulado, havendo igualmente partes de relevo suavemente ondulado e fortemente ondulado. A vegetação predominante na região é classificada como Floresta Ombrófila Mista AltoMontana (IBGE, 1992). Os solos predominantes são formados a partir de rochas de basalto, todos com baixa fertilidade natural. As principais classes de solos são Neossolos Litólicos e os Cambissolos. Os Neossolos Litólicos Húmicos típicos e Neossolos Litólicos Distróficos típicos são solos caracteristicamente rasos e ocupam geralmente as áreas de terço superior das encostas mais íngremes e os topos mais estreitos das elevações suavemente onduladas. Os Cambissolos Húmicos Distróficos lépticos e os Cambissolos Háplicos Distróficos úmbricos ocupam geralmente os terços médio e inferior e os patamares das encostas, sendo em geral pouco profundos.

O fragmento florestal estudado está localizado em uma propriedade rural, na localidade da Farofa, e é utilizado para o pastoreio extensivo de gado e o fornecimento de produtos não madeireiros, como o pinhão, para consumo próprio. $\mathrm{O}$ gado tem acesso a todo o fragmento florestal, porém, é possível observar que o pastoreio ocorre de forma preferencial em algumas áreas. Falkenberg (2003) cita que o impacto do gado sobre matas nebulares na região tem sido intenso devido ao hábito herbívoro e o pisoteio deste, o que ocasiona elevado consumo de fitomassa e aberturas de trilhas que prejudicam a regeneração natural.

\section{Coleta de dados}

Para a caracterização da comunidade arbórea, o fragmento florestal foi divido em setores, onde foram alocadas, de forma sistemática, 50 parcelas permanentes de $10 \times 20 \mathrm{~m}\left(200 \mathrm{~m}^{2}\right)$, totalizando 1 ha amostrado. No interior de cada setor, definido a partir de variações topográficas e sucessionais, as parcelas foram alocadas e distanciadas $30 \mathrm{~m}$ entre si. Em cada parcela, foram identificados e mensurados todos os indivíduos arbóreos e arbustivos com circunferência medida a altura do peito (CAP) igual ou superior a $15,7 \mathrm{~cm}$. Indivíduos com troncos múltiplos foram medidos quando a raiz da soma dos quadrados dos CAPs foi maior ou igual a $15,7 \mathrm{~cm}$. As identificações foram realizadas por meio de comparações em herbários 

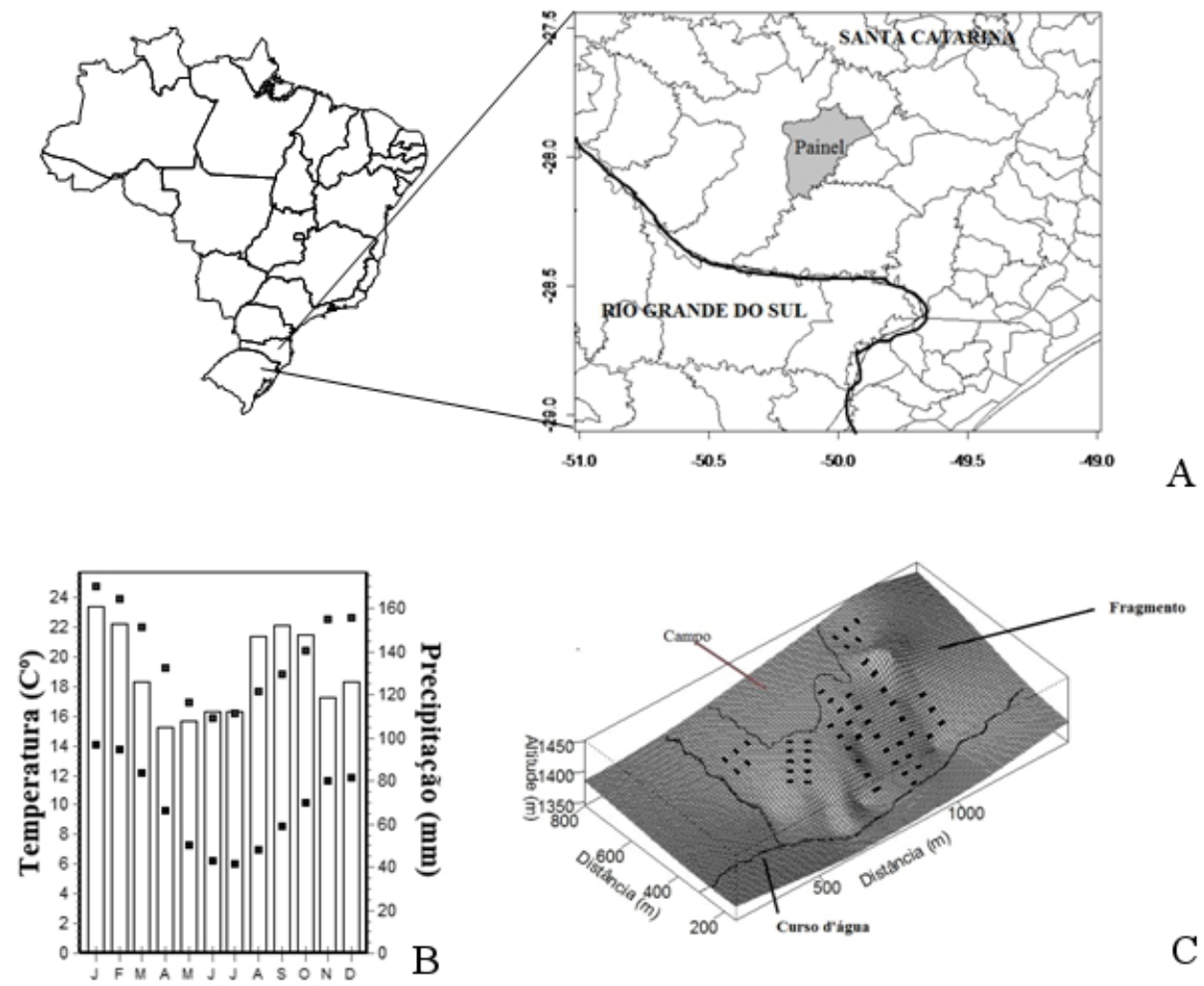

FIGURA 1: Localização da área de estudo (A), características climáticas, representada pela temperatura (pontos) e precipitação (barras) média mensal (B) e relevo da área e distribuição das parcelas (C), no município de Painel no estado de Santa Catarina, Brasil.

FIGURE 1: Location of study area (A), climate characteristics, represented by average monthly temperature (black dots) and precipitation (bars) (B), and topography of the area and distribution of the plots (C), in the municipality of the Paniel, Santa Catarina state, southern Brazil.

e literatura e as espécies de angiospermas foram classificadas nas famílias de acordo com o sistema APG III (ANGIOSPERM PHYLOGENY GROUP, 2009) e para a delimitação familiar de Pteridophyta utilizou-se o sistema de classificação de Tryon e Stolze (1989).

Os dados ambientais referentes ao solo e as variáveis topográficas foram coletados em cada parcela alocada. Foi obtida uma amostra composta, oriunda de quatro coletas realizadas no solo de 0 a $20 \mathrm{~cm}$. Destas amostras, foram realizadas análises das propriedades químicas e físicas no Laboratório de Análise de Solos do Centro de Ciências Agroveterinárias da Universidade do Estado de Santa Catarina - UDESC. Foi medido o pH em água e quantificados os teores de fósforo, potássio, cálcio, magnésio, sódio e alumínio extraíveis do solo. Com bases nestes valores, foram calculadas a CTC efetiva (t), a saturação por Al na CTC efetiva (m) e a soma de bases (S). Três variáveis topográficas foram coletadas em cada parcela: cota, desnível máximo e declividade média. A cota foi considerada como a média das quatro cotas dos vértices de cada parcela. O desnível máximo correspondeu à maior distância vertical entre os vértices das parcelas. A declividade média foi calculada por meio da média simples das declividades dos quatro lados da parcela retangular (OLIVEIRA FILHO et al., 1994). A avaliação da cobertura do dossel foi realizada por meio de quatro leituras, em direção ao norte, sul, leste e oeste, no centro de cada parcela, utilizando um densiômetro esférico (modelo A) côncavo (LEMMON, 1956), no período de novembro a dezembro de 2009.

\section{Análise dos dados}

A diversidade do fragmento estudado foi avaliada pelo índice de Shannon-Wiener ( $\left.\mathrm{H}^{\prime}\right)$ e equabilidade de Pielou (J') (BROWER e ZAR, 1984), e a composição florística foi analisada pelo estimador de riqueza Jackknife de primeira e 
segunda ordem (HELTSHE e FORRESTER, 1983), calculados pelo programa R (R DEVELOPMENT CORE TEAM, 2009).

Para a caracterização da estrutura foram calculados os parâmetros fitossociológicos para cada espécie (MUELLER-DOMBOIS e ELLEMBERG, 1974): densidade absoluta e relativa, frequência absoluta e relativa, dominância absoluta e relativa e valor de importância (VI). Também foi feita a distribuição diamétrica de toda a comunidade e das populações das espécies com VI acima de $5 \%$. As classes diamétricas da comunidade e das populações avaliadas e suas respectivas amplitudes de classes foram definidas pelo método estatístico.

Com o propósito de encontrar agrupamentos homogêneos, permitindo, desta forma, a análise indireta de gradientes ambientais, a abundância de indivíduos das espécies de cada parcela foi avaliada por meio da análise multivariada NMDS (Nonmetric Multidimensional Scaling), empregando quatro dimensões $(\mathrm{k}=4)$ (MINCHIN, 1987). A adequabilidade da ordenação para a análise foi avaliada por meio do valor de "stress", que é um indicativo da qualidade do ajuste (OKSANEN, 2010). Este é um método de ordenação não paramétrico, que plota as parcelas em um gráfico de dispersão, de forma que as distâncias euclidianas entre as parcelas são proporcionais à dissimilaridade entre elas (BABWETEERA e BROWN, 2009). Os vetores das variáveis significativas $(p<0,05)$ foram plotados a posteriori. No caso de variáveis ambientais redundantes e autocorrelacionadas, foram mantidas na análise aquelas de maior significância estatística. A análise NMDS foi feita no programa estatístico R (R DEVELOPMENT CORE TEAM, 2009) por meio da biblioteca Vegan (OKSANEN et al., 2009).

\section{RESULTADOS E DISCUSSÃO}

Foram amostrados 1.395 indivíduos arbóreos dentro das parcelas, que totalizaram uma área basal de 34,80 $\mathrm{m}^{2}$. Estes indivíduos pertencem a 50 espécies identificadas, distribuídas em 33 gêneros e 20 famílias botânicas, a um táxon da família Lauraceae e dois táxons do gênero Solanum não identificados em nível genérico e específico, respectivamente (Tabela 1) e a três espécimes não identificados devido à dificuldade de coleta.

As famílias com maior riqueza de espécies foram Myrtaceae (11), Solanaceae (9), Asteraceae (7), Aquifoliaceae (4) e Lauraceae (4). Myrtaceae,
TABELA 1: Espécies encontradas no fragmento de Floresta Ombrófila Mista AltoMontana localizado no município de Painel, SC, distribuídas em suas respectivas famílias botânicas.

TABLE 1: Species check-list in a highland Araucaria Forest fragment in municipality of Painel, Santa Catarina state, southern Brazil.

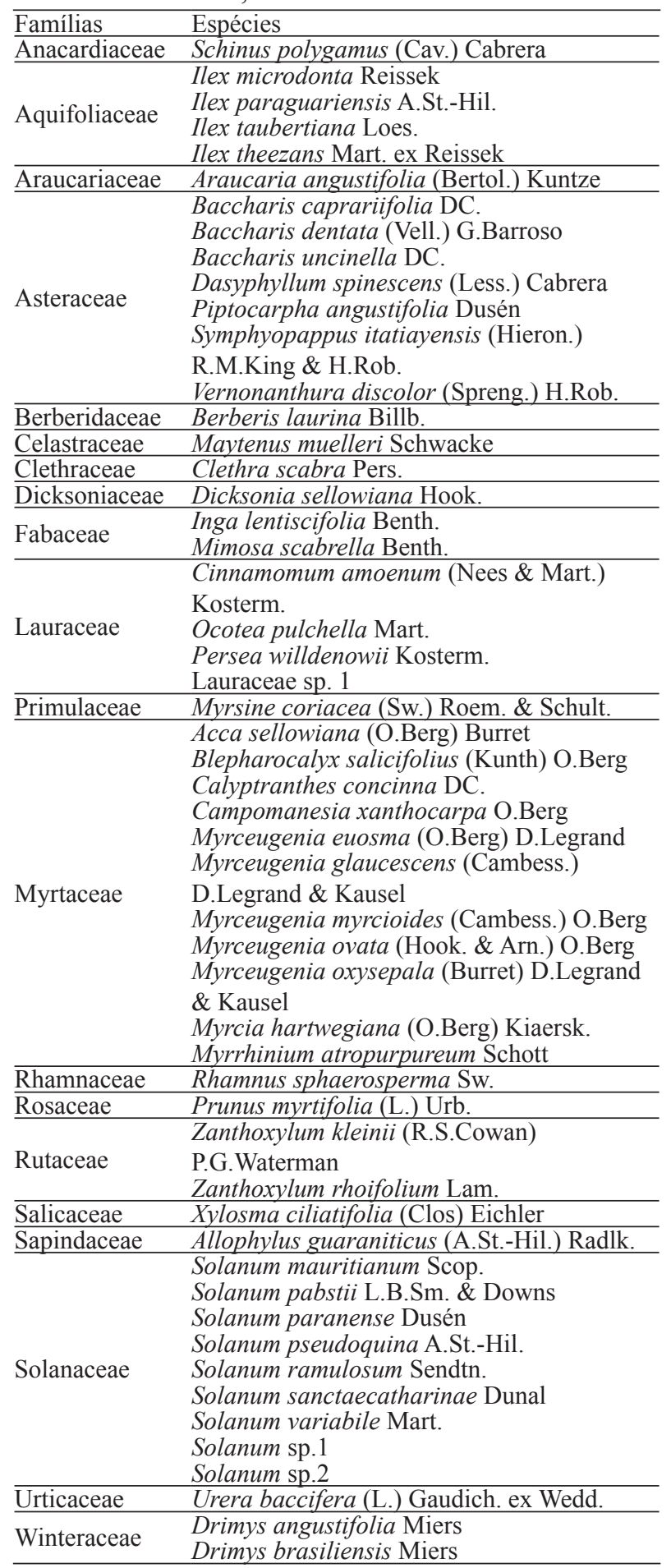


de maior riqueza de espécies, é uma das maiores famílias da flora brasileira (SOUZA e LORENZI, 2005). Muitos estudos em Florestas Ombrófilas Mistas, como os de Jarenkow e Batista (1987) e Nascimento et al. (2001), têm demonstrado Myrtaceae como a mais diversa em espécies arbóreas. Os gêneros com maior número de espécies foram Solanum (9), Myrceugenia (5), Ilex (4) e Baccharis (3). Também ocorreram neste fragmento os gêneros Drimys e Clethra, que Webster (1995) destacou como típicos de áreas nebulares neotropicais. A elevada riqueza dos gêneros Solanum e Baccharis pode ser um indicativo de que a área se apresenta em regeneração pós-distúrbio, uma vez que os gêneros supracitados apresentam várias espécies pioneiras e colonizadoras de áreas perturbadas.

Representantes de Fabaceae, típicos da formação de FOM, em altitudes acima de $800 \mathrm{~m}$ se destacaram no levantamento, como exemplo Mimosa scabrella, uma espécie pouco exigente quanto às características físicas dos solos e, como espécie pioneira, torna-se particularmente abundante nas matas antropizadas e contribuindo na ocupação de clareiras abertas pela exploração do pinheiro-brasileiro e outras árvores nativas (REITZ et al., 1988).

O índice de diversidade de Shannon indicou uma baixa diversidade de espécies $\left(\mathrm{H}^{\prime}=2,79\right)$, quando comparado com os valores encontrados em outros fragmentos de Floresta Ombrófila Mista (por ex.: $H^{\prime}=3,00$ no estudo de Nascimento et al. (2001) e 3,05 no estudo de Klauberg et al. (2010)). Isso se dá, provavelmente, devido à alta seletividade climática e edáfica de florestas alto-montanas. Por isso, a dominância de espécies foi relativamente alta $\left(\mathrm{J}^{\prime}=\right.$ $0,70)$. As 53 espécies encontradas (considerando os táxons identificados em nível de família, gênero ou espécie) representam 76,08\% a 64,46\% da riqueza esperada pelos estimadores Jackknife de primeira e segunda ordem, que tiveram valores de 69,66 e 82,22 espécies, respectivamente. A diferença entre a riqueza observada e estimada pode ter ocorrido em função da elevada heterogeneidade florística do fragmento estudado, em função das variações espaciais ambientais e de estágios sucessionais.

As espécies com maior VI foram: Araucaria angustifolia (17,32 \%), Myrceugenia euosma (15,24\%), Acca sellowiana (7,84\%), Dicksonia sellowiana (7,27 \%), Drimys brasiliensis (7,00\%) e Myrceugenia oxysepala (5,80\%), conforme a Tabela 2.

Apesar do maior VI, Araucaria angustifolia contribui com pouco mais da metade do número de indivíduos de Myrceugenia euosma, espécie de maior densidade na área estudada. A sua elevada importância relativa se deu em função da elevada dominância $(31,12 \%)$, sendo representada por grandes indivíduos que formam o dossel superior da floresta. Por outro lado, Myrceugenia euosma é representada por indivíduos menores que formam o dossel abaixo dos indivíduos dominantes de araucária, mas apresenta maior frequência que Araucaria angustifolia, ocorrendo em $84 \%$ das parcelas.

A Araucaria angustifolia, embora sendo a única espécie comum e de grande porte, que ocupa o dossel superior, na área de estudo, não se apresenta de forma contínua e, portanto, não promove o sombreamento completo do sub-bosque. Desta forma, as espécies que ocorrem no dossel inferior, como Myrceugenia euosma, Acca sellowiana, Drimys brasiliensis e Myrceugenia oxysepala, recebem luz direta em muitos locais. Estas espécies são bem distribuídas no fragmento, pois todas ocorreram em mais da metade das parcelas alocadas. Já Dicksonia sellowiana, que apresentou o quarto maior VI, demonstrou ser de ocorrência restrita, registrada em $30 \%$ das parcelas, em locais mais úmidos, situados, muitas vezes, somente na encosta sul das florestas. A condição de maior umidade para o crescimento e desenvolvimento de populações de Dicksonia sellowiana foi relatada por Sehnem (1978) e reforçada por Mantovani (2004), afirmando que esta espécie cresce em locais pantanosos (alta umidade), próximo a riachos e em encostas íngremes de face sul (menor insolação).

A estrutura diamétrica de toda a comunidade obteve distribuição próxima ao "J invertido" (Figura 2), o que é esperado em florestas naturais. Das seis populações de espécies com VI acima de $5 \%$ que tiveram a distribuição diamétrica calculada, cinco, Araucaria angustifolia, Myrceugenia euosma, Acca sellowiana, Drimys brasiliensis e Myrcengenia oxysepala, também obtiveram padrões de distribuição diamétrica próximos ao "J invertido" (Figura 3). Somente Dicksonia sellowiana, a única pteridófita encontrada, demonstrou um padrão de distribuição próximo a normal. Esse fato é devido a muitos indivíduos apresentarem diâmetro de inclusão, mas sua altura ser inferior a $1,30 \mathrm{~m}$, portanto não contemplado na análise dos dados.

Os valores médios das variáveis ambientais analisadas encontram-se na Tabela 3. Os atributos químicos dos solos foram similares aos indicados 
TABELA 2: Espécies amostradas em um fragmento de Floresta Ombrófila Mista Alto-Montana no Município de Painel, SC, ordenadas pelo valor de importância (VI, em \%). DA = densidade absoluta; DR $=$ densidade relativa, em \%; DoA $=$ dominância absoluta, em $\mathrm{m}^{2} / \mathrm{ha}$; DoR $=$ dominância relativa, em \%; FA = frequência absoluta, em \%; FR = frequência relativa, em \%.

TABLE 2: Sampled species in a highland Araucaria Forest fragment in the municipality of Panel, Santa Catarina State, Southern Brazil, ordered by importance value (VI,\%). DA = absolute density; $\mathrm{DR}=$ relative density, in $\%$; DoA $=$ absolute dominance in $\mathrm{m}^{2} / \mathrm{ha}$, DoR $=$ relative dominance in $\%, \mathrm{FA}=$ absolute frequency, in $\%, \mathrm{RF}=$ relative frequency in $\%$.

\begin{tabular}{|c|c|c|c|c|c|c|c|}
\hline Espécie & $\mathrm{DA}$ & DR & DoA & DoR & FA & FR & VI \\
\hline Araucaria angustifolia (Bertol.) Kuntze & 170 & 12,19 & 10,8301 & 31,12 & 80 & 8,66 & 17,32 \\
\hline Myrceugenia euosma (O.Berg) D.Legrand & 326 & 23,37 & 4,6144 & 13,26 & 84 & 9,09 & 15,24 \\
\hline Acca sellowiana (O.Berg) Burret & 160 & 11,47 & 1,7131 & 4,92 & 66 & 7,14 & 7,84 \\
\hline Dicksonia sellowiana Hook. & 82 & 5,88 & 4,4190 & 12,70 & 30 & 3,25 & 7,27 \\
\hline Drimys brasiliensis Miers & 119 & 8,53 & 1,7011 & 4,89 & 70 & 7,58 & 7,00 \\
\hline Myrceugenia oxysepala (Burret) D.Legrand \& Kausel & 98 & 7,03 & 1,3521 & 3,89 & 60 & 6,49 & 5,80 \\
\hline Cinnamomum amoenum (Nees \& Mart.) Kosterm. & 34 & 2,44 & 2,6368 & 7,58 & 32 & 3,46 & 4,49 \\
\hline Ocotea pulchella Mart. & 46 & 3,30 & 1,1156 & 3,21 & 38 & 4,11 & 3,54 \\
\hline Ilex paraguariensis A.St.-Hil. & 45 & 3,23 & 0,3732 & 1,07 & 48 & 5,19 & 3,16 \\
\hline Drimys angustifolia Miers & 46 & 3,30 & 0,7350 & 2,11 & 32 & 3,46 & 2,96 \\
\hline Schinus polygamus (Cav.) Cabrera & 28 & 2,01 & 0,2975 & 0,85 & 34 & 3,68 & 2,18 \\
\hline Myrceugenia ovata (Hook. \& Arn.) O.Berg & 28 & 2,01 & 0,2781 & 0,80 & 32 & 3,46 & 2,09 \\
\hline Mimosa scabrella Benth. & 9 & 0,65 & 1,2764 & 3,67 & 16 & 1,73 & 2,01 \\
\hline Calyptranthes concinna DC. & 21 & 1,51 & 0,2656 & 0,76 & 22 & 2,38 & 1,55 \\
\hline Ilex microdonta Reissek & 12 & 0,86 & 0,3520 & 1,01 & 16 & 1,73 & 1,20 \\
\hline Prunus myrtifolia (L.) Urb. & 13 & 0,93 & 0,3027 & 0,87 & 16 & 1,73 & 1,18 \\
\hline Myrsine coriacea (Sw.) Roem. \& Schult. & 9 & 0,65 & 0,3898 & 1,12 & 16 & 1,73 & 1,17 \\
\hline Persea willdenowii Kosterm. & 7 & 0,50 & 0,4236 & 1,22 & 14 & 1,52 & 1,08 \\
\hline Myrceugenia myrcioides (Cambess.) O.Berg & 17 & 1,22 & 0,1519 & 0,44 & 14 & 1,52 & 1,06 \\
\hline Berberis laurina Billb. & 13 & 0,93 & 0,0525 & 0,15 & 18 & 1,95 & 1,01 \\
\hline Inga lentiscifolia Benth. & 10 & 0,72 & 0,1697 & 0,49 & 14 & 1,52 & 0,91 \\
\hline Zanthoxylum rhoifolium Lam. & 11 & 0,79 & 0,1751 & 0,50 & 12 & 1,30 & 0,86 \\
\hline Xylosma ciliatifolia (Clos) Eichler & 9 & 0,65 & 0,0632 & 0,18 & 16 & 1,73 & 0,85 \\
\hline Solanum ramulosum Sendtn. & 9 & 0,65 & 0,0556 & 0,16 & 16 & 1,73 & 0,85 \\
\hline Solanum variabile Mart. & 9 & 0,65 & 0,0549 & 0,16 & 16 & 1,73 & 0,84 \\
\hline Ilex taubertiana Loes. & 5 & 0,36 & 0,3014 & 0,87 & 8 & 0,87 & 0,70 \\
\hline Symphyopappus itatiayensis (Hieron.) R.M.King \& H.Rob. & 8 & 0,57 & 0,0282 & 0,08 & 12 & 1,30 & 0,65 \\
\hline Blepharocalyx salicifolius (Kunth) O.Berg & 5 & 0,36 & 0,0654 & 0,19 & 10 & 1,08 & 0,54 \\
\hline Solanum paranense Dusén & 5 & 0,36 & 0,0136 & 0,04 & 10 & 1,08 & 0,49 \\
\hline Baccharis dentata (Vell.) G.Barroso & 5 & 0,36 & 0,0218 & 0,06 & 6 & 0,65 & 0,36 \\
\hline Dasyphyllum spinescens (Less.) Cabrera & 3 & 0,22 & 0,0301 & 0,09 & 6 & 0,65 & 0,32 \\
\hline Myrrhinium atropurpureum Schott & 3 & 0,22 & 0,0254 & 0,07 & 6 & 0,65 & 0,31 \\
\hline Não identificada & 3 & 0,22 & 0,1003 & 0,29 & 4 & 0,43 & 0,31 \\
\hline Zanthoxylum kleinii (R.S.Cowan) P.G.Waterman & 2 & 0,14 & 0,1672 & 0,48 & 2 & 0,22 & 0,28 \\
\hline Baccharis caprariifolia DC. & 3 & 0,22 & 0,0176 & 0,05 & 4 & 0,43 & 0,23 \\
\hline Solanum pabstii L.B.Sm. \& Downs & 2 & 0,14 & 0,0197 & 0,06 & 4 & 0,43 & 0,21 \\
\hline Allophylus guaraniticus (A.St.-Hil.) Radlk. & 2 & 0,14 & 0,0181 & 0,05 & 4 & 0,43 & 0,21 \\
\hline Rhamnus sphaerosperma $\mathrm{Sw}$. & 2 & 0,14 & 0,0051 & 0,01 & 4 & 0,43 & 0,20 \\
\hline Solanum pseudoquina A.St.-Hil. & 1 & 0,07 & 0,0377 & 0,11 & 2 & 0,22 & 0,13 \\
\hline Solanum mauritianum Scop. & 1 & 0,07 & 0,0347 & 0,10 & 2 & 0,22 & 0,13 \\
\hline Lauraceae sp.1 & 1 & 0,07 & 0,0282 & 0,08 & 2 & 0,22 & 0,12 \\
\hline Vernonanthura discolor (Spreng.) H.Rob. & 1 & 0,07 & 0,0193 & 0,06 & 2 & 0,22 & 0,11 \\
\hline Campomanesia xanthocarpa O.Berg & 1 & 0,07 & 0,0147 & 0,04 & 2 & 0,22 & 0,11 \\
\hline Myrcia hartwegiana (O.Berg) Kiaersk. & 1 & 0,07 & 0,0100 & 0,03 & 2 & 0,22 & 0,11 \\
\hline Solanum sp. 2 & 1 & 0,07 & 0,0093 & 0,03 & 2 & 0,22 & 0,10 \\
\hline Clethra scabra Pers. & 1 & 0,07 & 0,0069 & 0,02 & 2 & 0,22 & 0,10 \\
\hline Piptocarpha angustifolia Dusén & 1 & 0,07 & 0,0065 & 0,02 & 2 & 0,22 & 0,10 \\
\hline Baccharis uncinella DC. & 1 & 0,07 & 0,0058 & 0,02 & 2 & 0,22 & 0,10 \\
\hline Solanum sanctaecatharinae Dunal & 1 & 0,07 & 0,0039 & 0,01 & 2 & 0,22 & 0,10 \\
\hline Solanum sp.1 & 1 & 0,07 & 0,0039 & 0,01 & 2 & 0,22 & 0,10 \\
\hline Urera baccifera (L.) Gaudich. Ex Wedd. & 1 & 0,07 & 0,0029 & 0,01 & 2 & 0,22 & 0,10 \\
\hline Maytenus muelleri Schwacke & 1 & 0,07 & 0,0024 & 0,01 & 2 & 0,22 & 0,10 \\
\hline Myrceugenia glaucescens (Cambess.) D.Legrand \& Kausel & 1 & 0,07 & 0,0024 & 0,01 & 2 & 0,22 & 0,10 \\
\hline Ilex theezans Mart. ex Reissek & 1 & 0,07 & 0,0022 & 0,01 & 2 & 0,22 & 0,10 \\
\hline
\end{tabular}




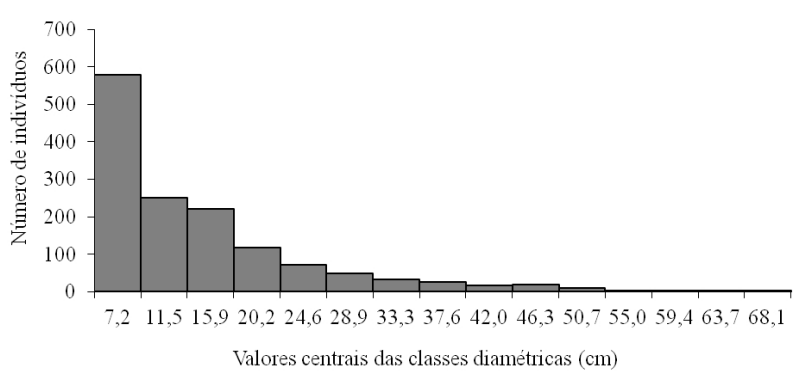

FIGURA 2: Estrutura diamétrica da comunidade de um fragmento de Floresta Ombrófila Mista Alto-Montana em Painel, SC.

FIGURE 2: Diameter structure of the tree community in a highland Araucaria Forest fragment in the municipality of Painel, Santa Catarina state, southern Brazil. para Cambissolos e Neossolos Litólicos para a região de Painel e Urupema no Mapa de Solos do Estado de Santa Catarina (EMBRAPA, 2004), revelando tratar-se de solos ácidos, com elevados teores de alumínio trocável e baixa soma de bases, baixos teores de fósforo e médios de potássio, indicando condição de baixa fertilidade química. De acordo com a classificação proposta por Souza (2007), apesar de a declividade média indicar uma área com relevo ondulado $\left(10,47^{\circ}\right)$, existiu uma grande variação no fragmento, desde locais planos $\left(0^{\circ}\right)$ até forte ondulada $\left(21,70^{\circ}\right)$. A cobertura do dossel, quando comparado com outro fragmento de Floresta Ombrófila Mista (60 \%) (MEDRI et al., 2009), que utilizou a mesma metodologia de avaliação, pode ser considerada alta.
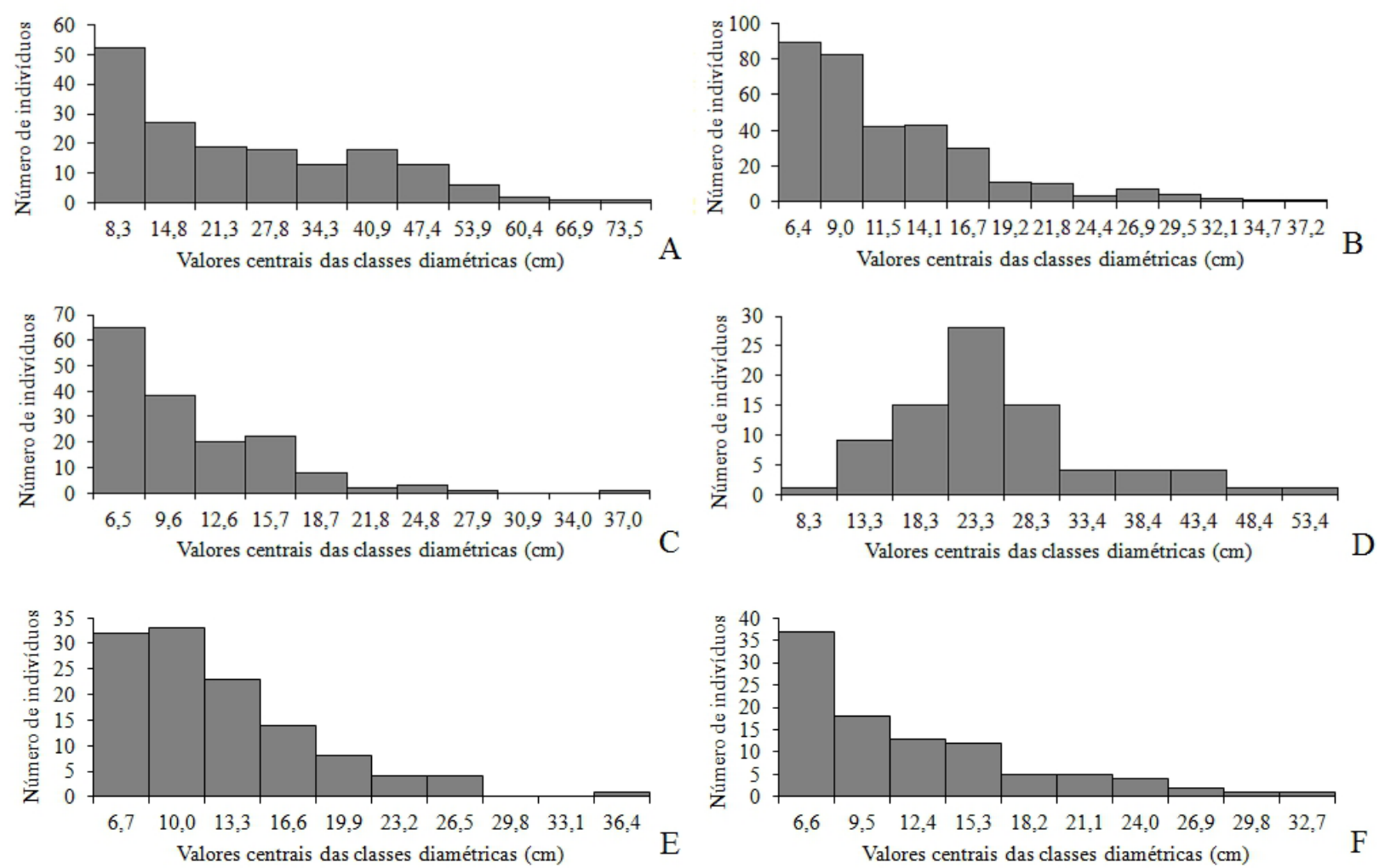

FIGURA 3: Estrutura diamétrica das populações das espécies com VI acima de $5 \%$ em um fragmento de Floresta Ombrófila Mista Alto-Montana em Painel, SC. A = Araucaria angustifolia (Bertol.) Kuntze; B = Myrceugenia euosma (O.Berg) D.Legrand; C = Acca sellowiana (O.Berg) Burret; $\mathrm{D}=$ Dicksonia sellowiana Hook.; $\mathrm{E}=$ Drimys brasiliensis Miers; F = Myrceugenia oxysepala (Burret) D.Legrand \& Kausel.

FIGURE 3: Diameter structure of tree populations with VI above $5 \%$ in a highland Araucaria Forest fragment in the municipality of Painel, Santa Catarina state, southern Brazil. A = Araucaria angustifolia (Bertol.) Kuntze, B = Myrceugenia euosma (O. Berg) D. Legrand, C = Acca sellowiana (O. Berg) Burret $\mathrm{D}=$ Dicksonia sellowiana Hook., $\mathrm{E}=$ Drimys brasiliensis Miers, $\mathrm{F}=$ Myrceugenia oxysepala (Burret) D. Legrand \& Kausel. 
A ordenação dos dados produzida pela NMDS e a variáveis ambientais significativas podem ser observadas na Figura 4. O valor de "stress" encontrado foi de 13,58, o que indica que a ordenação é adequada para a interpretação. É possível observar que o componente arbóreo apresentou variações estruturais e florísticas associadas à heterogeneidade ambiental, representada pelas variáveis de teores de argila no solo (arg), declividade média (decmed), desnível máximo (desmax), cota média (cotmed) e cobertura do dossel (CD).

A espécie Acca sellowiana, espécie bastante apreciada pelas comunidades rurais em função de seus frutos, ocorreu preferencialmente nos locais com maiores teores de argila, mais baixos (menor cota média) e com o dossel mais aberto (menor CD), preferencialmente nas parcelas, $3,5,12,13,14,15$,

TABELA 3: Valores médios e desvio padrão das variáveis ambientais analisadas em 50 parcelas alocadas em um fragmento de Floresta Ombrófila Mista AltoMontana em Painel, SC. Valor de $p$ indica a significância das variáveis em relação à ordenação dos dados florístico-estruturais do componente arbóreo.

TABLE 3: Mean values of environmental variables analyzed within 50 plots allocated in a highland Araucaria Forest fragment in the municipality of Painel, Santa Catarina state, southern Brazil.

\begin{tabular}{lccc}
\hline Variáveis & Média & $\begin{array}{c}\text { Desvio } \\
\text { Padrão }\end{array}$ & $P$ \\
\hline Argila (\%) & 26,18 & 5,79 & 0,002997 \\
$\mathrm{pH}$ & 4,19 & 0,39 & 0,137862 \\
$\mathrm{P}\left(\mathrm{mg} \mathrm{dm}^{-3}\right)$ & 9,63 & 8,72 & 0,993007 \\
$\mathrm{Al}^{3+}\left(\mathrm{cmol}_{\mathrm{c}} \mathrm{dm}^{-3}\right)$ & 5,22 & 3,23 & 0,530470 \\
$\mathrm{Ca}^{2+}\left(\mathrm{cmol}_{\mathrm{c}} \mathrm{dm}^{-3}\right)$ & 2,61 & 2,29 & 0,299700 \\
$\mathrm{Mg}^{2+}\left(\mathrm{cmol}_{\mathrm{c}} \mathrm{dm}^{-3}\right)$ & 0,87 & 0,74 & 0,153846 \\
$\mathrm{~K}\left(\mathrm{mg} \mathrm{dm}^{-3}\right)$ & 77,79 & 52,69 & 0,059940 \\
$\mathrm{SB}\left(\mathrm{cmol}_{\mathrm{c}} \mathrm{dm}^{-3}\right)$ & 3,68 & 3,05 & 0,265734 \\
Saturação por Al (\%) & 63,44 & 23,46 & 0,127872 \\
$\mathrm{CTC}$ efetiva $\left(\mathrm{cmol} \mathrm{cm}^{-3}\right)$ & 8,92 & 4,35 & 0,170829 \\
Declividade média & 10,47 & 6,04 & 0,003996 \\
(graus) & 4,60 & 3,65 & 0,014985 \\
Desnível máximo (m) & $1.399,36$ & 34,09 & 0.000999 \\
Cota média (m) & 90,61 & 8,55 & 0,012987 \\
Cobertura do Dossel (\%) & & &
\end{tabular}

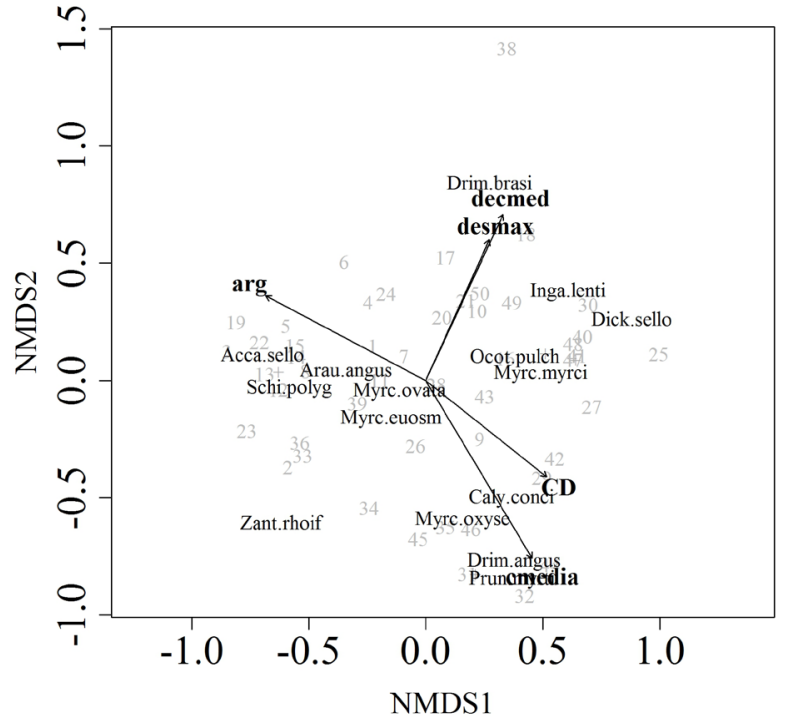

FIGURA 4: Distribuição das parcelas e das variáveis ambientais estudadas em um fragmento de Floresta Ombrófila Mista Alto-Montana em Painel, SC, na análise de NMDS (Nonmetric Multidimensional Scaling). $\mathrm{CD}=$ cobertura do dossel; cmedia = cota média; arg = teor de argila; decmed = declividade média; desmax $=$ desnível máximo. Acca.sello: Acca sellowiana, Arau.angus: Araucaria angustifolia, Caly.conci: Calyptranthes concinna, Dick.sello: Dicksonia sellowi, Drim.angus: Drimys angustifolia Drim. brasi: Drimys brasiliensis, Inga.lenti: Inga lentiscifolia, Myrc.euosm: Myrceugenia euosma, Myrc.ovata: Myrceugenia ovata, Myrc.oxyse: Myrceugenia oxysepala, Prun.myrt: Prunus myrtifolia, Schi. polyg: Schinus polygamus, Zant.rhoif: Zanthoxylum rhoifolium.

FIGURE 4: NMDS (Nonmetric Multidimensional Scaling) analysis showing the distribution of plots and environmental variables in a highland Araucaria Forest fragment in the municipality of Painel, Santa Catarina State, Southern Brazil. CD = canopy cover; Cmedia = mean elevation; $\arg =$ clay content; decmed = average slope; desmax = maximum declivity. Acca.sello: Acca sellowiana, Arau.angus: Araucaria angustifolia, Caly.conci: Calyptranthes concinna, Dick.sello: Dicksonia sellowi, Drim.angus: Drimys angustifolia Drim. brasi: Drimys brasiliensis, Inga.lenti: Inga lentiscifolia, Myrc.euosm: Myrceugenia euosma, Myrc.ovata: Myrceugenia ovata, Myrc.oxyse: Myrceugenia oxysepala, Prun.myrt: Prunus myrtifolia, Schi. polyg: Schinus polygamus, Zant.rhoif: Zanthoxylum rhoifolium. 
19 e 22 . No outro extremo deste gradiente ambiental, representados pelos locais com menores teores de argila, com maiores cotas médias e com maior cobertura do dossel, ocorreram preferencialmente as espécies Calyptranthes concinna, Drimys angustifolia, Myrceugenia oxysepala e Prunus myrtifolia. Outro gradiente ambiental evidenciado foi o associado à declividade média (decmed) e desnível máximo (desmax). Enquanto Drimys brasiliensis se destacou nos locais mais declivosos, Zanthoxylum rhoifolium teve uma participação destacada nos locais mais planos. Myrceugenia euosma, a espécie com a maior frequência no local, situou-se no centro do diagrama de ordenação, não apresentando correlação com nenhuma variável ambiental avaliada, o que pode ser um indicativo de que esta espécie apresenta menor exigência ambiental na área de estudo. Interessante ressaltar também a segregação espacial de Drimys brasiliensis e Drimys angustifolia, consideradas por vários autores como sendo uma única espécie. Se de fato for uma única espécie, o presente estudo indica que Drimys brasiliensis pode assumir características morfológicas diferenciadas em função do ambiente em que ocorre. No entanto, se forem consideradas espécies distintas, como no presente caso, os resultados indicam que ambas apresentam uma segregação espacial, ocupando nichos diferentes, o que reduziria a competição entre si.

A influência de variáveis topográficas, de características físicas do solo e da cobertura do dossel sobre a estrutura do componente arbóreo tem sido relatada frequentemente na literatura na região sudeste (e.g. ESPIRITO-SANTO et al., 2002, CARVALHO et al., 2005, RODRIGUES et al., 2007, TEIXEIRA e ASSIS, 2009) e sul do Brasil (e.g. BUDKE et al., 2007), o que demonstra ser este um padrão comum em fragmentos florestais pertencentes ao domínio atlântico.

\section{CONCLUSÕES}

Myrtaceae, Solanaceae, Asteraceae, Aquifoliaceae, Lauraceae e Solanaceae foram as famílias de maior riqueza, com predominância de espécies dos gêneros Myrceugenia, Solanum, Baccharis e Ilex. A diversidade foi baixa e a dominância alta, com dominância ecológica de Araucaria angustifolia no dossel superior e de Myrceugenia euosma no dossel inferior. A estrutura diamétrica de toda a comunidade e a das populações estudadas (exceto Dicksonia sellowiana) obtiveram distribuição próxima ao "J invertido".

A análise NMDS revelou que peculiaridades do meio físico condicionam as variações na florística e na estrutura da comunidade, demonstrando maior porcentagem de argila nas parcelas de maior densidade de Acca sellowiana e menor porcentagem, nas parcelas de maior densidade de Dicksonia sellowiana, Inga lentiscifolia e Ocotea pulchella. As parcelas de maior declividade tiveram maior densidade de Drimys brasiliensis e aquelas de menor declividade, maior cota e maior cobertura do dossel, tiveram maior ocorrência de Drimys angustifolia, Prunus myrtifolia, Calyptranthes concinna e Myrceugenia oxysepala.

\section{AGRADECIMENTOS}

Ao CNPq, pelo auxílio financeiro, por meio do Edital MCT/CNPq 15/2007, que permitiu o desenvolvimento desse trabalho.

\section{REFERÊNCIAS BIBLIOGRÁFICAS}

APG III. An update of the Angiosperm Phylogeny Group classification for the orders and families of flowering plants: APG III. Botanical Journal of the Linnean Society, v. 161, n. 2, p. 105-121. 2009. BABWETEERA, F.; BROWN, N. Can remnant frugivore species effectively disperse tree seeds in secondary tropical rain forests? Biodiversity and Conservation, v. 18, n. 6, p. 1611-1627. 2009.

BROWER, J. E.; ZAR, J. H. Field and laboratory methods for general ecology. Duduque: W.M.C. Brow Publishers. 1984. 84 p.

BUDKE, J. C. et al. Relatioships between tree component structure, topography and soils of a riverside forest, Rio Botucaraí, Southern Brazil. Plant Ecology, v. 189, p. 189-200. 2007.

CARVALHO, D. A. et al. Variações florísticas e estruturais do componente arbóreo de uma floresta ombrófila alto-montana às margens do rio Grande, Bocaina de Minas, MG, Brasil. Acta Botanica Brasilica, v. 19, n. 1, p. 91-109, 2005.

EMBRAPA. Centro Nacional de Pesquisa de Solos. Manual de métodos de análises de solo. 2. ed. Rio de Janeiro: EMBRAPA. 1997. 212 p.

EMBRAPA. Embrapa Solos. Solos do Estado de Santa Catarina Rio de Janeiro: EMBRAPA. 2004. 721 p. (Boletim de Pesquisa e Desenvolvimento, 46).

ESPÍRITO-SANTO, E. D. B. et al. Variáveis ambientais e a distribuição de espécies arbóreas em 
um remanescentes de floresta estacional montana em Lavras, MG. Acta botanica brasílica, v. 16, n. 3, p. 331-351. 2002.

FALKENBERG, D. Matinhas nebulares e vegetação rupícola dos Aparados da Serra Geral (SC/RS), sul do Brasil. 2003. 558 f. Tese (Doutorado em Biologia Vegetal) - Universidade Estadual de Campinas, Campinas, 2003.

GOMES, M. et al. Classificação das áreas de recarga do sistema Aqüífero Guarani no Brasil em domínios pedomorfoagroclimáticos-subsídio aos estudos de avaliação de risco de contaminação das águas subterrâneas. Revista do Departamento de Geografia, v. 18, p. 67-74. 2006.

HELTSHE, J. F. e FORRESTER, N. E. Estimating species richness using the jackknife procedure. Biometrics, v. 39, p. 1-12. 1983.

IBGE. Manual técnico da vegetação brasileira. Rio de Janeiro: Fundação Instituto Brasileiro de Geografia e Estatística, 1992. 92 p. (Série: Manuais técnicos em geociências n.1).

JARENKOW, J. A.; BAPTISTA, L. R. M. Composição florística e estrutura da mata com araucária na Estação Ecológica de Aracuri, Esmeralda, Rio Grande do Sul. Napaea, Porto Alegre, v. 3, p. 9-18. 1987.

KLAUBERG, C. et al. Florística e estrutura de um fragmento de Floresta Ombrófla Mista no Planalto Catarinense. Biotemas, v. 23, n. 1, p. 35-47. 2010.

KLEIN, R. M. Mapa fitogeográfico de Santa Catarina. In: REITZ, R. Flora Ilustrada de Santa Catarina. Itajaí: Herbário Barbosa Rodrigues. 1978. 24 p.

KOEHLER, A. et al. Floresta Ombrófila Densa Altomontana: aspectos florísticos e estruturais de diferentes trechos da serra do mar. Ciência Florestal, v. 12, n. 2, p. 27-39. 2002.

LEMMON, P. A spherical densiometer for estimating forest overstory density. Forest Science, v. 2, n. 4, p. 314-320. 1956.

MANTOVANI, M. Caracterização de populações naturais de Xaxim (Dicksonia sellowiana (Presl.) Hooker), em diferentes condições edafo-climáticas no Estado de Santa Catarina. 2004. 105 f. Dissertação (Mestrado em Recursos Genéticos Vegetais)-Universidade Federal de Santa Catarina, Florianópolis, 2004.

MEDRI, P. et al. Comparação de parâmetros bióticos e abióticos entre fragmento de floresta secundária e reflorestamento de Araucaria angustifolia (Bertol.) O. Kuntze. Semina: Ciências Biológicas e da Saúde, v. 30, n. 2, p. 185-194. 2009.
MINCHIN, P. R. An evaluation of relative robustness of techniques for ecological ordinations. Vegetatio, v. 71, p. 145-156. 1987.

MULLER-DOMBOIS, D.; ELLENBERG, H. Aims and of vegetation ecology. New York: John Wiley \& Sons. 1974. 547 p.

NASCIMENTO, A. R. T. et al. Estrutura e padrões de distribuição espacial de espécies arbóreas em uma amostra de Floresta Ombrófila Mista em Nova Prata, RS. Ciência Florestal, Santa Maria, v. 11, n. 1, p. 105-119. 2001.

OKSANEN, J. et al. Vegan: community ecology package. $\mathrm{R}$ package version, v.1, p. 8-8. 2009.

OKSANEN, J. Multivariate Analysis of Ecological Communities in R: vegan tutorial. 2010. 43 p.

OLIVEIRA FILHO, A. T. et al. Differenciation of streamside and upland vegetation in an area of montane semideciduous Forest in southeastern Brasil. Flora, v. 189, p. 1-19. 1994.

R DEVELOPMENT CORE TEAM. R: A language and environment for statistical computing. R Foundation for Statistical Computing, 2008. Disponível em: <(http://www.R-project.org) $>$ Acesso em: 18 de fevereiro de 2009.

RODRIGUES, L. A. et al. Efeitos de solos e topografia sobre a distribuição de espécies arbóreas em um fragmento de floresta estacional semidcidual, em Luminarias, MG. Revista Árvore, v. 31, n. 1, p. 25-35. 2007.

SANTA CATARINA. Secretaria de Estado de Coordenação Geral e Planejamento. Subsecretaria de Estudos Geográficos e Estatísticos. Atlas Escolar de Santa Catarina. Rio de Janeiro: Aerofoto Cruzeiro, 1986. 36 p.

SEHNEM, A. Ciateáceas. In: REITZ, R. Flora Ilustrada de Santa Catarina. Itajaí: Herbário Barbosa Rodrigues. 1978. 114 p.

SGROTT, E. Fitossociologia da zona ripária no Estado de Santa Catarina. In: SEMINÁRIO DE HIDROLOGIA FLORESTAL: ZONAS RIPÁRIAS, 1., 2003, Alfredo Wagner. Anais... Florianópolis: Universidade Federal de Santa Catarina, 2003. p. 14-39.

SOUZA, C. G. Manual técnico de pedologia. Rio de Janeiro: Fundação Instituto Brasileiro de Geografia e Estatística, 2007. 104 p. (Série: Manuais Técnicos em Geociências v.4).

SOUZA, V. C.; LORENZI, H. Botânica Sistemática: guia ilustrado pra identificação das famílias de Angiospermas da flora brasileira, baseado em APG II. Nova Odessa: Instituto 
Plantarum, 2005. $640 \mathrm{p}$.

TEIXEIRA, A.; ASSIS, M. A. Relação entre heterogeneidade ambiental e distribuição de espécies em uma floresta paludosa no Município de Cristais Paulistas, SP, Brasil. Acta Botanica Brasilica, v. 23, n. 3, p. 843-853. 2009.

TRYON, R. M.; STOLZE, R. G. Pteridophyta of Peru. Part I. Ophioglossaceae - Cyatheaceae. Fieldiana Botany N. S., v. 20, p. 1-145. 1989.

WEBSTER, G. L. The panorama of Neotropical cloud forests. In: NEOTROPICAL MONTANE FORESTBIODIVERSITYAND CONSERVATION SYMPOSIUM, 1995, New York. Proceedings... Davis: University of California, 1995. p. 53-77. 